RESEARCH PAPER RP959

Part of Journal of Research of the National Bureau of Standards, Volume 18
January 1937

\title{
A MICROBURETTE FOR TESTING THE ABSORPTIVENESS OF THIN PAPER
}

\author{
By F. T. Carson
}

\section{ABSTRACT}

A microburette, designed to measure and deliver a hundredth milliliter of liquid, is described and illustrated. It consists of a capillary tube, with a sliding index, mounted so that the capillary can be adjusted to any angle of inclination such that the column of liquid in the capillary advances the length of the slider, and thereby displaces a measured volume which then hangs as a small drop from the discharge tip. A mechanism is provided for transferring the pendent drop to the specimen. Although designed particularly for use in the testing of thin absorbent paper, the microburette can probably be adapted to other uses requiring the accurate dispensing of small amounts of liquids.

I. Introduction

II. Description of the microburette

III. Operation of the microburette $\ldots \ldots \ldots 4$

IV. Calibration of the microburette

V. Concluding remarks_.......... 45

\section{INTRODUCTION}

Absorptiveness is the property of chief importance in some types of paper. Blotting paper has for many years been tested by measuring the absorption time of 1 milliliter of standard ink when delivered in a specified manner on the surface of the paper. Paper towels were formerly tested by this technique for blotting paper, water being substituted for the ink. For a satisfactory test of paper towels, however, a milliliter of water has been found too much, and for still thinner absorbent papers it is out of the question.

In the ordinary use of a paper towel, for example, a small volume of water is spread out thinly over a considerable area of the towel, and is absorbed quickly by penetrating for the most part straight into the sheet. The normal behavior could scarcely be simulated in a test that deposits at a given place so large an amount of water that most of it must be absorbed by spreading out and creeping laterally through the structure of the paper to a considerable distance from the point of origin, as must necessarily occur when a milliliter is poured at a given point on a sheet as thin as a paper towel. Loss by evaporation, when the time for absorption is thus prolonged, is also a source of uncertainty, and in some cases the uncertainty of the test is intensified by part of the water dropping from the underside of the specimen. Improvement in the test has required the application of smaller amounts of water to the specimen. Betterment in this direction, 
however, has been somewhat hindered by the difficulty of accurately measuring and delivering much smaller amounts of water at a given point on the paper. Apparatus have been described within the last 3 or 4 years that are capable of delivering $0.1 \mathrm{ml}$, or somewhat less, with sufficient accuracy to a given position on the specimen, ${ }^{1}$ and the use of such apparatus has increased the reliability and meaning of tests of the absorbent quality of paper towels.

For a satisfactory test of yet thinner paper, however, a still smaller amount of water is required. The microburette here described is designed to measure and deliver $10 \mathrm{~mm}^{3}$, or $0.01 \mathrm{ml}$, of liquid reproducibly to a predetermined position on the specimen, and is intended to fill the requirement for a means of testing very thin absorbent papers, such as toilet paper, facial tissue, paper napkins, and the like.

\section{DESCRIPTION OF THE MICROBURETTE}

The instrument illustrated in the photograph of figure 1 and the drawing of figure 2 consists of a glass capillary tube, $C$, about 10 inches long, about a quarter of an inch in outside diameter, with a bore about 0.03 inch $(3 / 4 \mathrm{~mm})$ in diameter, and having a special mounting adapted to the testing of sheets of paper. One end of the capillary tube is drawn out so that the tip $D$ is about $1 / 16$ inch in diameter. It is then bent so that a $1 / 4$-inch length at the tip-end is vertical when the capillary tube is inclined at an angle of about $30^{\circ}$ with the horizontal. The capillary tube is mounted with two axes of rotation, both of which are horizontal but mutually perpendicular, allowing it to be inclined at a suitable angle and also to be moved vertically without altering the angle of inclination. It is clamped to a counterweighted supporting arm, $A$, that is provided with a friction pivot, $F$, to hold it at any desired angle of inclination from zero to about $60^{\circ}$. Inclining the capillary tube so as to make liquid in it either flow out, or come to rest with the meniscus at any desired point, serves the purpose of the stopcock in the usual form of burette.

Although, ideally, the axis about which the capillary rotates in changing its angle of inclination should pass through the discharge tip, in order that the tip will remain at the same level, regardless of the angle of inclination of the capillary tube, it was not found practical in the construction of the instrument to realize this coincidence of axis and tip, because the discharge tip is almost in contact with the specimen when the liquid is delivered. The axis of the pivot, $F$, is therefore placed slightly above the discharge tip, $D$, yet near enough that the tip will remain at substantially the same level throughout the working range of inclination of the capillary tube.

The microburette is not graduated with fixed reference lines in the customary manner, but is provided with a sliding dual index, $R$, that spans a length of the column of liquid in the capillary corresponding to the volume of $10 \mathrm{~mm}^{3}$ used in testing the thin absorbent papers. This amount of water when measured from the microburette hangs as a small drop from the delivery tip and slightly above the specimen of paper to be tested.

To provide a mechanism for bringing the pendent drop into contact with the paper, the microburette is fastened to the base through the

1 Carson and Worthington, Paper Trade J. 95, TS188 (1932),
Reese and Youtz, Paper Trade J. 100, TS67 (1935).

Krogh, J. Ind. Eng. Chom., Anal. Ed. \%, 130 (1235). 


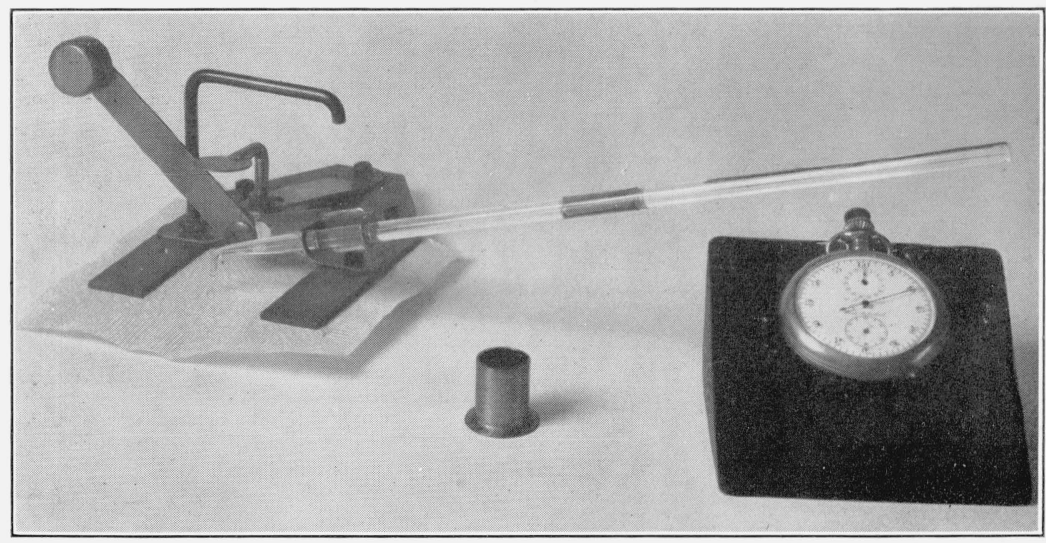

Figure 1.-The microburette. 

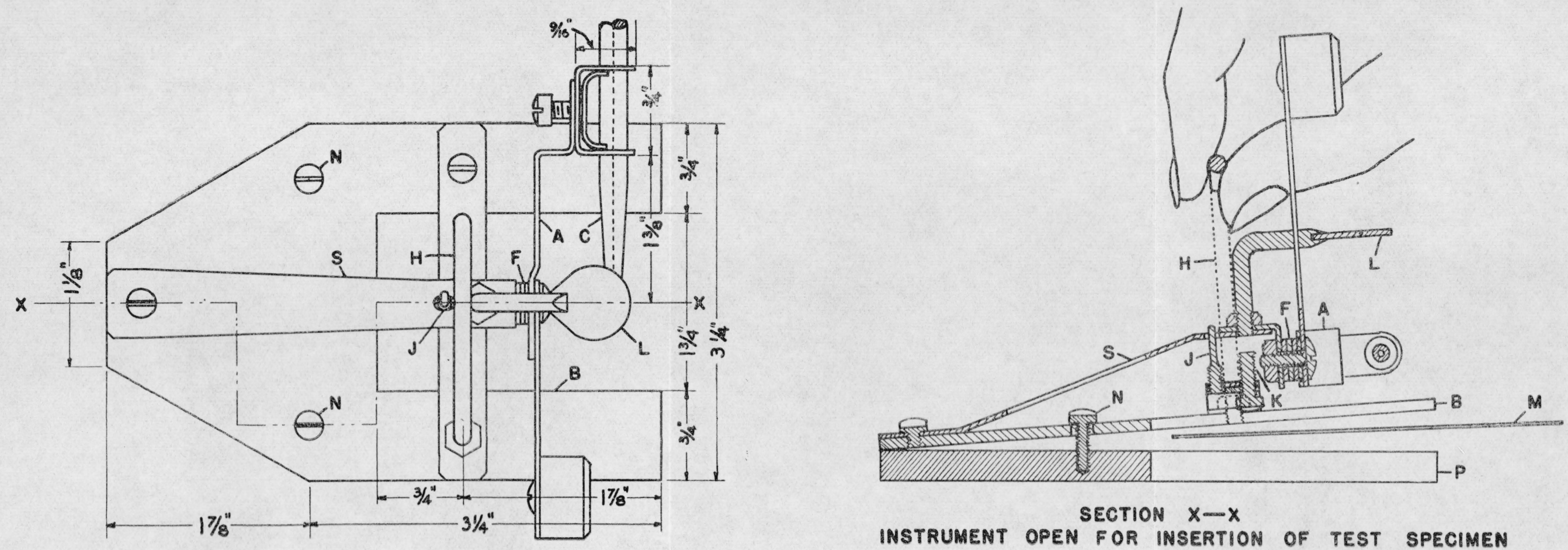

\section{A-COUNTERWEIGHTED SUPPORT}

\section{B-BASE}

C - CAPILLARY

D-DISCHARGE TIP

F-FRICTION DISKS

H-HANDLE

$J$-UPPER STOP

$K$-LOWER STOP

L-LEVER

$M-T E S T$ SPECIMEN

N-HINGE BOLT

P-PLATE

R-SLIDING DUAL INDEX

S-LEAF SPRING

T-FILLING THIMBLE

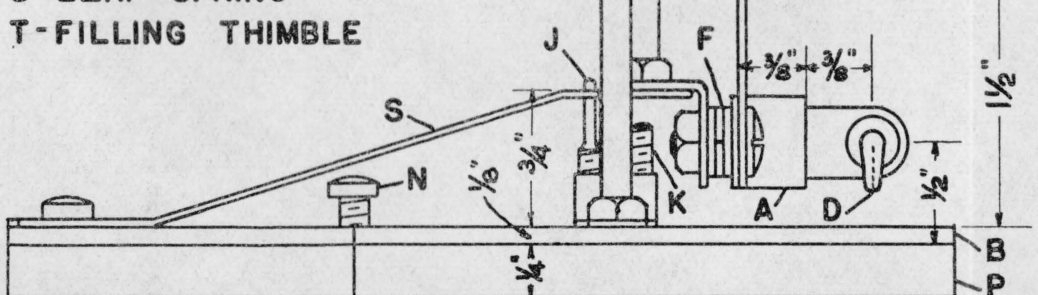

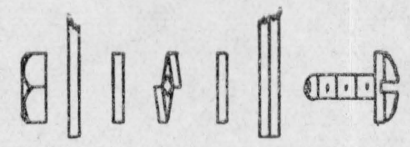

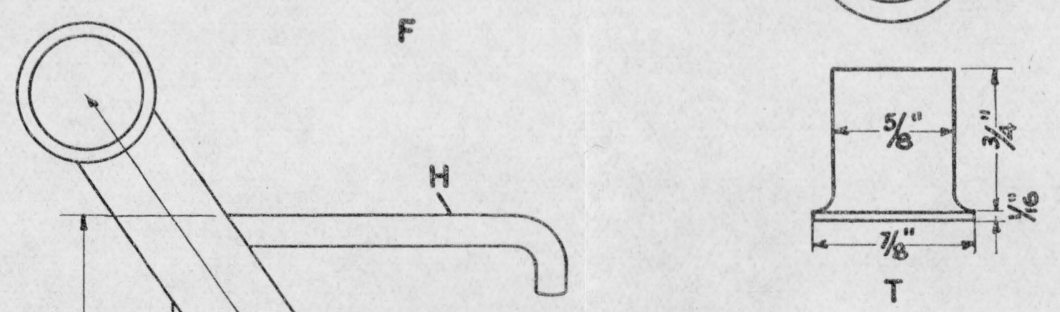

FIgURE 2.-Detailed drawing of the microburette.
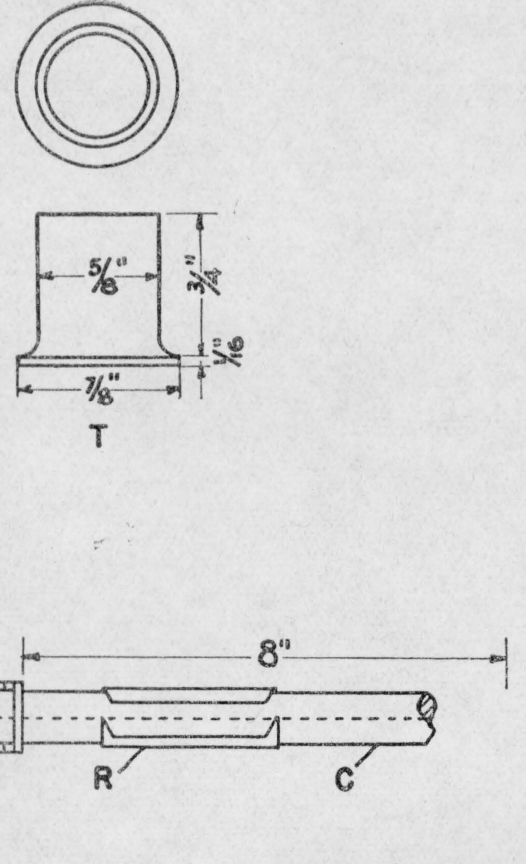
medium of a stiff leaf spring, $S$ (fig. 2), provided with adjustable stops, $J$ and $K$. While the drop is being measured the spring rests against the upper stop, $J$, which is so adjusted that the discharge tip is held about $3 / 16$ inch above the specimen. When, however, the spring is pressed down against the lower stop, $K$, by depressing the lever, $L$, the capillary tube is lowered as a whole without altering the angle of inclination, the discharge tip being brought within about 1/16 inch of the specimen. This adjustment allows the drop to touch the specimen without being distorted objectionably. The drop of water

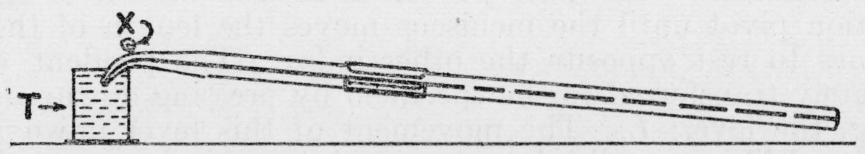

a

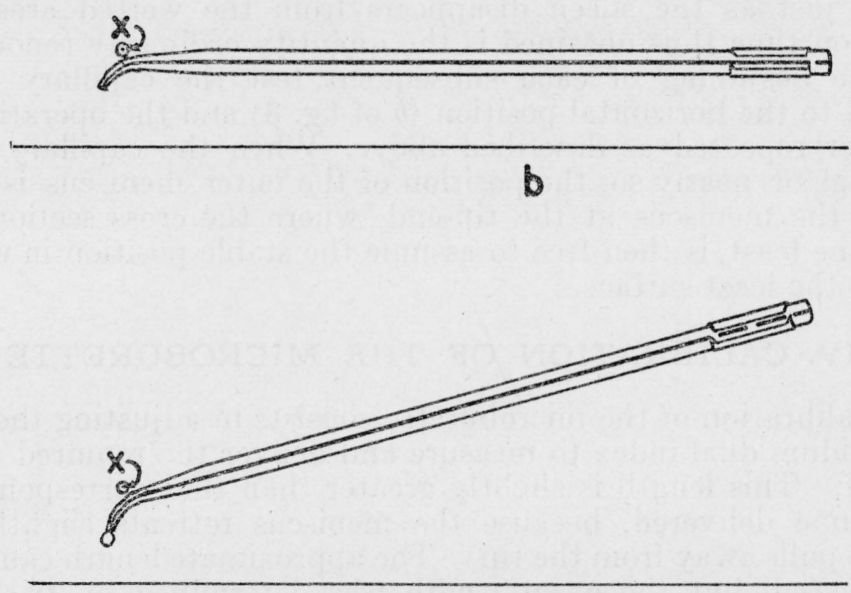

c

FIGURe 3.-Diagram of filling position (a), starting position (b), and delivery position (c) of the microburette.

The axis of inclination is at $X$.

adheres to the paper and is pulled away from the tip of the microburette as the lever is released.

The specimen, $M$, is clamped in place below the discharge tip by the weight of the instrument. It is held between the base, $B$, of the mounting and an underlying plate, $P$, similar to the base, $B$, and hinged to it by means of screws, $N$, that extend through slots in the base, $B$, and allow the plate, $P$, to fall away slightly from the base when the instrument is lifted by the handle, $H$. The clamp is thus opened for inserting the specimen, $M$. 


\section{OPERATION OF THE MICROBURETTE}

The capillary tube is filled in position $a$ of figure 3. The tip, is immersed in distilled water ${ }^{2}$ contained in the thimble, $T$, and the other end is lowered, whereupon the water siphons over and fills the capillary. All water is then wiped from the exterior with absorbent cloth or paper.

The capillary tube is next moved to the horizontal position ( $b$ of fig. 3 ) and the outer index of the slider, $R$, is moved into coincidence with the meniscus. The microburette is then rotated ( $c$ of fig. 3 ) on the friction pivot until the meniscus moves the length of the slider and comes to rest opposite the other index. The pendent drop is immediately transferred to the specimen by pressing down, and then releasing, the lever, $L$. The movement of this lever down and up should be deliberate, allowing the drop to be in contact with the specimen about a second before the discharge tip is withdrawn from it, and avoiding vibration on releasing the lever. The whole operation of measuring the drop and delivering it to the specimen should require less than half a minute. Loss by evaporation during this length of time is negligibly small. The microburette will deliver five or more $10-\mathrm{mm}^{3}$ portions before it requires refilling.

A stop watch is started when the drop touches the paper, and is stopped just as the sheen disappears from the wetted area. The absorption time thus obtained is the quantity ordinarily reported.

At the beginning of each subsequent test the capillary tube is returned to the horizontal position ( $b$ of fig. 3 ) and the operations are thereafter repeated as described above. When the capillary tube is horizontal or nearly so, the position of the outer meniscus is stable, because the meniscus at the tip-end, where the cross section of the bore is the least, is then free to assume the stable position in which it presents the least surface.

\section{CALIBRATION OF THE MICROBURETTE}

The calibration of the microburette consists in adjusting the length of the sliding dual index to measure and deliver the required amount of liquid. This length is slightly greater than that corresponding to the volume delivered, because the meniscus retreats slightly after the drop pulls away from the tip. The approximate length can readily be estimated, but the exact length was determined by trial. The drop delivered was weighed in a weighing bottle, and the length between temporary marks on a slider was adjusted until the average of several successive trials corresponded to the required amount of water. When the exact length had been determined, a metal slider was made with two fixed indices separated by the correct distance.

The uncertainty in a particular delivery is around 5 percent, but the average uncertainty in several successive deliveries is small. An example of the performance of the microburette, calibrated to deliver $10 \mathrm{~mm}^{3}$, is shown in table 1 . Since it is customary to make at least 10 tests per sample, the error resulting from uncertainty in the amount of water delivered is small in the mean value for the sample.

${ }^{2}$ Although distilled water is not necessary to the testing of the absorptiveness of paper, its use will help to avoid difficulty in flling the capillary, since otherwise the bore is likely to become gradually encrusted with a deposit from impure water that will make it difficult to wet. In an extremity, of course, flling can be effected by suction on the end with a medicine-dropper bulb. Likewise, to prevent fouling with organic matter, the capillary should be emptied after use. Emptying is easily effected by holding a piece of blotting paper against the discharge tip. 
TABLE 1.-Data showing the reproducibility in several successive trials

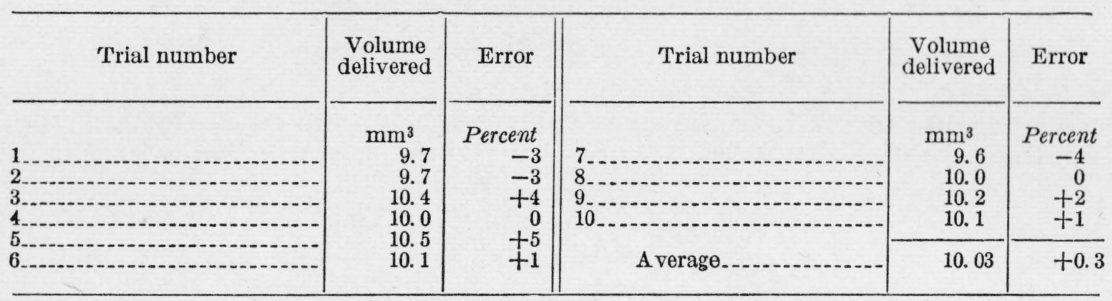

\section{CONCLUDING REMARKS}

Although the $10-\mathrm{mm}^{3}$ drop deposited on the specimen by the microburette results in a fairly good test of the absorptiveness of the class of papers for which the instrument was designed, it might be desirable to use a still smaller drop in testing some tissue papers. Likewise, in the test of paper towels for absorptiveness, the conditions of absorption in use would be better simulated and other advantages would result, such as a shorter test period, if the customary $0.1 \mathrm{ml}$ of water were replaced by a considerably smaller volume. The microburette, which is designed to dispense a tenth of this amount, is, therefore, recommended for consideration in the revision of specifications or in further improvement of the test of the absorptiveness of paper towels.

The instrument which has been described was designed for the testing of a particular kind of paper, and the test has been used in Federal specifications for about 3 years. Although designed to meet a specific requirement, the microburette can probably be easily adapted to the measurement of somewhat greater or smaller volumes, to the dispensing of various liquids, and to the requirements of other uses involving the precise dispensing of small amounts of liquids.

Washington, October 27, 1936. 